\title{
132 ：画像の時空間微分を用いた流場の計測手法とその応用
}

\author{
大阪府立大学 奥野 武俊，西尾，茂，杉井，康彦 $\mathrm{O}$ \\ Image Measurement System through the Spatio-Temporal Derivatives \\ of Visualized Images and Its Applications
}

Taketoshi OKUNO; Shigeru NISHIO*and Yasuhiko SUGII ${ }^{\dagger}$

\begin{abstract}
The change of luminance of visualized image is caused by the motion of tracer particles or dyne transported by fluid, and it is expressed by a governing equation using the Lagrange's derivatives. The so-called spatio-temporal derivative method is well known as an image measurement technique which has a high spatial resolution. The technique also has disadvantages such as small dynamic range and the unsteadiness for the image noise. In the present paper, the principles of the measurement techniques based on the spatio-temporal derivatives are explained, and the applications are shown. The spatio-temporal derivative method would have much wide application field.
\end{abstract}

\section{1 緒 言}

可視化画像の輝度変化は、トレーサー粒子や染料など が流体に輸送されることによって引き起こされ、この変 化はLagrange微分を用いた画像の拘束式として記述する ことができる。この画像の拘束式を用いて画像の移動量 （オプティカルフロー）を計测する手法は、Horn[1]、安藤 [2]、三池 [3] らによって手法の整備・搪張がなされてきた。 これらの手法は勾配法とも呼ばれ、高い空間解像度をも つ手法として知られている。しかし、画像の空間周波数に 対する画像の移動距離の制限からダイナミックレンジが 狭いことやノイズに鋭敏であるなど、画像に対する制約 が多いことから流場計測の分野では必す゚しも広く用いら れているとはいえない状況にある。

時空閒微分法は、画像の条件が整えば他の手法では解 析不能な微小な画像の変化や移動、粒子密度の極端に高 い画像などの解析が可能である。著者らは時空間微分法 を流場計測に適用する試みを続けており、これまでに速 度場のみならず壁面摩擦応力、流場モデルを用いた計測 など時空間微分法の特性を生かした応用分野の開拓を行っ てきた。本論文では、時空間微分法の原理と、それから派 生する計测手法ならびに応用について述べる。

\footnotetext{
*Department of Marine System Engineering, Osaka Prefecture University, Sakai, Osaka 593

Traduate School of Osaka Prefecture University
}

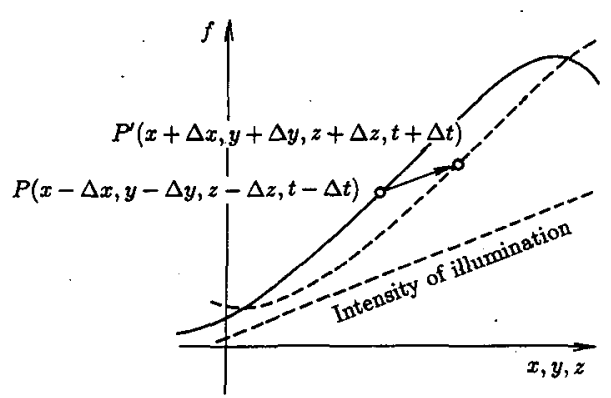

Fig.1 Measurement principle of the spatio-temporal derivative method.

\section{2 時空間徽分法の計測原理}

トレーサー粒子や染料を用いて流れを可視化した場合、 可視化された情報は場所 $(x, y, z)$ と時刻 $t$ を变数にもつ輝 度関数 $f(x, y, z, t)$ で表わすことができる。Fig.1に示すよ うに、時刻 $t か ら ら t+\Delta t$ の間にトレーサーが流体によって 輸送され $(\Delta x, \Delta y, \Delta z)$ だけ移動したとき、移動前後の輝 度変化は(1)式のように表わされる。

$$
\begin{aligned}
& f(x+\Delta x, y+\Delta y, z+\Delta z, t+\Delta t) \\
& \quad \quad-f(x-\Delta x, y-\Delta y, z-\Delta z, t-\Delta t) \\
& =\Delta g(x, y, z, t)
\end{aligned}
$$

ここで、 $g(x, y, z, t)$ はバックグラウンドの場を表わす関数 て、、可視化の場合には照明強度に相当し、 $\Delta g$ は時間的な らびに空間的な照明強度の変化を示す。さて、画像の楎度 
変化が滑らかであるとすると輝度関数はTaylor 展開可能 となり、(2)式のように表わせる。

$$
\begin{aligned}
& f(x+\Delta x, y+\Delta y, z+\Delta z, t+\Delta t) \\
& =f(x, y, z, t)+\frac{\partial f}{\partial x} \Delta x+\frac{\partial f}{\partial y} \Delta y+\frac{\partial f}{\partial z} \Delta z+O\left(\delta^{2}\right) .
\end{aligned}
$$

また、 $(\Delta x, \Delta y, \Delta z)$ は $\Delta t$ における流体粒子の移動量であ るから、流速 $\boldsymbol{u}(u, v, w)$ を用いて次のように表現できる。

$$
\Delta x=u(x, y, z) \Delta t+O\left(\delta^{2}\right) .
$$

$\Delta y, \Delta z$ につても同様の展開ができるから、(3)式を(2) 式に代入して $\Delta t \rightarrow 0$ の極限における輝度変化を考えると、 画像の拘束式が微分方程式として求めることができる。

$$
\frac{\partial f}{\partial t}+u \frac{\partial f}{\partial x}+v \frac{\partial f}{\partial y}+w \frac{\partial f}{\partial z}=\lim _{\Delta t \rightarrow 0} \frac{\Delta g(x, y, z, t)}{2 \Delta t} .
$$

(4) 式右辺は、通常可視化の条件を整えてなるべく小さく するように努めて、解析の時には近似的に0として扱うこ とが多い。また、照明強度の変化が大きくて右辺が無視で きない場合には、何らかの検定を行ってその分布を求めた 上で拘束式に加える必要がある。また、ここでは $\Delta t \rightarrow 0$ の極限において画像の拘束式を求めたが、実際の計測に おいては $\Delta t$ が有限であるから、(2),(3)式の高次の項は必 ずしも無視できるほど小さいとは限らないので、これら の展開式における高次近似項を考慮した解法も提案され ている $[4]_{0}$

(4) 式の解を求めるには、輝度值ならびにその勾配が可 視化画像から得られているので流速 $\boldsymbol{u}(u, v, w)$ を末知数と して解けばよいが、(4)式単独では条件が不足する。した がって、計測におろいて流速を求めるときには、空間的に狭 い領域において速度が一定と仮定するなどの条件を付加 し、これにより得られる連立方程式から速度ベクトルを 求める。この付加条件については、空間的な速度の均一 性だけでなく他の条件を考えることによって、派生的に 新しい解法が得られる。例えば、時間的な定常性を仮定 して各画素単位で速度ベクトルを求める統計的な解法や、 連続の式などの物理的な法則を付加した流場モデルを用 いる方法などがそれであるが、これらについては後節で 述べる。

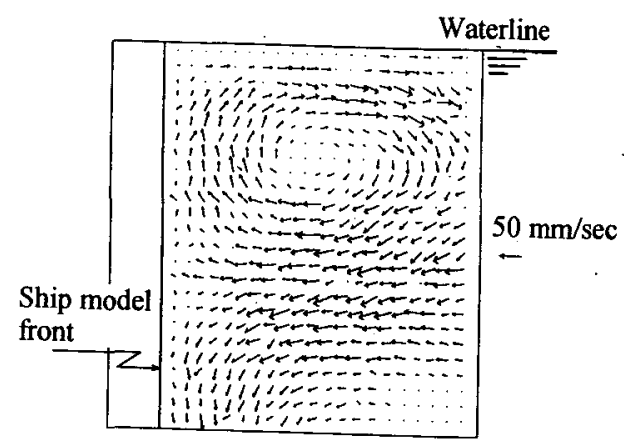

Fig.2 Measured velocity field around a ship model.
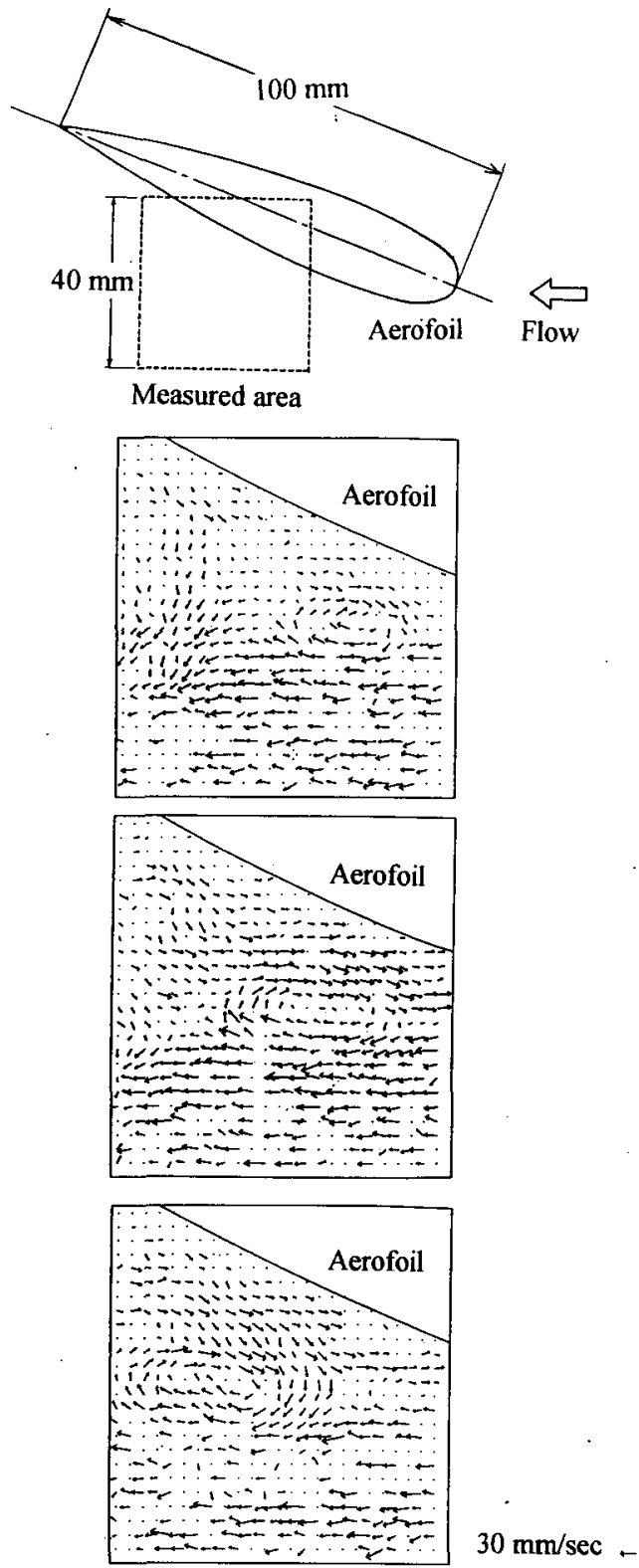

Fig. 3 Measured velocity field around a wing model.

\section{3 流場計測への庶用}

空間的には流場の変化が大きくない場合には、狭い領域 において流速を一定とみない、その領域内で流速 $u(u, v, w)$ を未知数とする連立方程式の解を最小二乗法などを用い て求めることができる。このとき、画像ノイズの影響を低 減させることも同時に行うために、10×10 $\mathrm{pixel}^{2}$ 程度の解 析領域を設けるのが通常である。

Fig.2は、船体模型まわりの流れの計測例である $[5]$ 。船 首前方の中心面をトレーサー粒子とレーザーシート光を 用いて可視化し、速度場を求めた。船首水面近くには、首 飾り渦が形成されることはよく知られているが、本計測 においては首飾り渦の断面を表わす流れのパターンが得 られていることがわかる。Fig.3は翼背面の計測例である。 


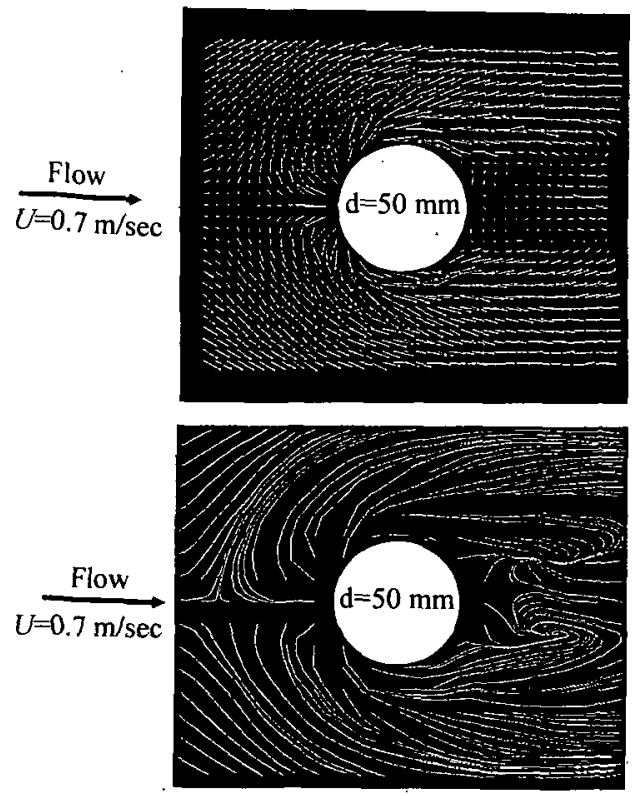

Fig. 4 Measured wall shear stress and the limiting stream lines.

翼前端付近で生成された渦が、後流に流れ士る様子がべ クトル分布図からわかる。

\section{4 壁面摩擦応力の計測}

時空間微分法を速度場の計測に適用する場合、計測可 能な画像の移動距離は画像の空閒周波数によって制限を 受け、計測のダイナミックレンジは必ずしも広いとは言え ない。逆に、画像の移動距離が非常に小さくて数ピクセル 以下の場合には、サブピクセルオーダ一の空間解像度を もつ時空間微分法は他の手法では不可能な計測を可能と する。

物体表面に塗布した油膜は、壁面の摩擦応力によって ゆっくりと移動する。この移動速度を求めると、摩擦応 力の分布と限界流線の計測を行うことができる $[6]$ 。油膜 の塗布には、従来限界流線の可視化法として用いられて きた油膜法の手順を踏警し、まずエンジンオイルを表面 に薄く塗り、その上から流動パラフィンにオレイン酸と顔 料を混ぜたものを押しつけるようにして塗る。このよう にすると、油膜の移動と共に顔料の移動が可視化できる。 ここで、従来の油膜法と異なるのは、油膜法が限界流線を 可視化するために流線方向の筋方現れるまで10 20分程 度の時間を要したのに刘し、本計測では油膜の移動を画 像計測するので計測は1〜2分のごく短時間に行われるこ とである。Fig.4は、円柱が壁面に垂直に取り付けられた 時の壁面摩擦心力の分布と計測された摩擦心力から計算 した限界流線である。この接合部流れにおいては、壁面 近くに円柱を取りまくように渦が発生する。本計测にお いては限界流線からみられるように円柱背面に渦状点が

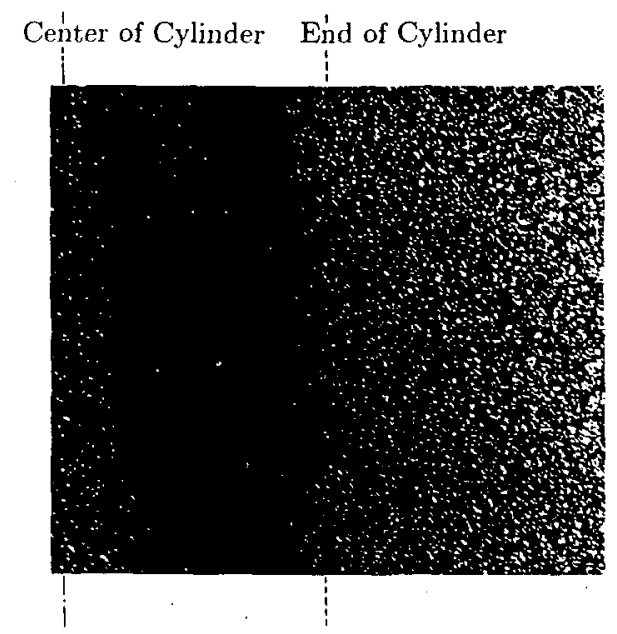

Fig.5 Measured wake distribution by means of statistical analysis.

現れることから、円柱前方の壁面近くで生成される渦が、 円柱後方で壁面から離れる方向に流れ出ていることがわ かる。

\section{5 統計的解析手法を用いた計測}

可視化画像の拘束式(1)を、流れの方向に $\xi$ をもつ流線 座標 $(\xi, \eta, \zeta)$ で晴きがると、 $u_{\eta}=u_{\zeta}=0$ であるから、

$$
\frac{\partial f}{\partial t}+u_{\xi} \frac{\partial f}{\partial \xi}=\lim _{\Delta t \rightarrow 0} \frac{\Delta g(\xi, \eta, \zeta, t)}{\Delta t}
$$

となる。このとき、 $u_{\xi}$ が定常で怔とおくことができ、過 程がエルゴード性を满たすならば、

$$
\left|\bar{u}_{\xi}\right|=\frac{E\left[\left|\frac{\partial f}{\partial t}\right|\right]}{E\left[\left|\frac{\partial f}{\partial \xi}\right|\right]}
$$

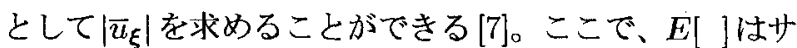
ンプルデータの集合平均を表わし、(5)式右辺の極限は十 分に小さいと仮定している。(6)式注、可視化画像の時間 微分と空間微分の絶対值の比が流速に比例し、画像の統 計処理により流速分布が求められることを示している。

従来の解法が、速度の空間的な均一性を仮定して速度 ベクトルを求めていたのに対して、本解法法時間的な定 常性を仮定し、Lかも支配方程式の係数を統計的に処理 することにより、流速を求めている。Fig.5に円柱後流の 伴流分布の計測例を示主。Fig.5において、明るい部分は 流速の大きな領域を示し、暗い部分は流速の小さな領域 を示す。ここでは、流速の絶対值のみを求める解法を示し たが、画像の拘束式をべクトル演算とみなして統計的に 処理することにより、速度べクトルを求める手法の開発も 行われている $[8]$ 。 


\section{6 - 流場モデルを用いた解法}

これまでにも述べたように、(4)式で表わされる画像の 拘束式は、それ単独では条件不足から速度べクトルを求 めることはできない。従来は時間的または空間的な速度 場の均一性を仮定した付加条件を用いることにより速度 場を求めてきが、計測対象が流場であることから流場の もつ物理的な性質を付加条件として用いることもできる [9]。ここでは、画像の拘束式に加える付加条件として非 圧縮性流体の連続の式、さらに局所的には粘性の影響は 小さいとして非粘性の渦度の輸送方程式を用いた。

$$
\begin{aligned}
& \frac{\partial f}{\partial t}+u \frac{\partial f}{\partial x}+v \frac{\partial f}{\partial y}=0 \\
& \frac{\partial u}{\partial x}+\frac{\partial v}{\partial y}=0 \\
& u \frac{\partial \omega}{\partial x}+v \frac{\partial \omega}{\partial y}=0
\end{aligned}
$$

この場合、速度場に関する 1 階ならびに 2 階の偏微分方程 式が付加されているため、繰り返し計算や最適化の手順 を経て速度場が求められる。Fig.6は、流れに垂直に置か れた円柱後流の速度場を計測した例で、一様流速 $U=0.05$ $\mathrm{m} / \mathrm{sec}$ でレイノルズ数 $R n=1472$ の場合である。流場モデ ルを用いた場合と局所的な速度の均一性を仮定した従来 の方法を比較すると、速度場の大きな改善をべクトル図 からみることは難しいが、連続の式のノルムが $84 \%$ 、渦 度方程式のノルムが $91 \%$ 減少している。

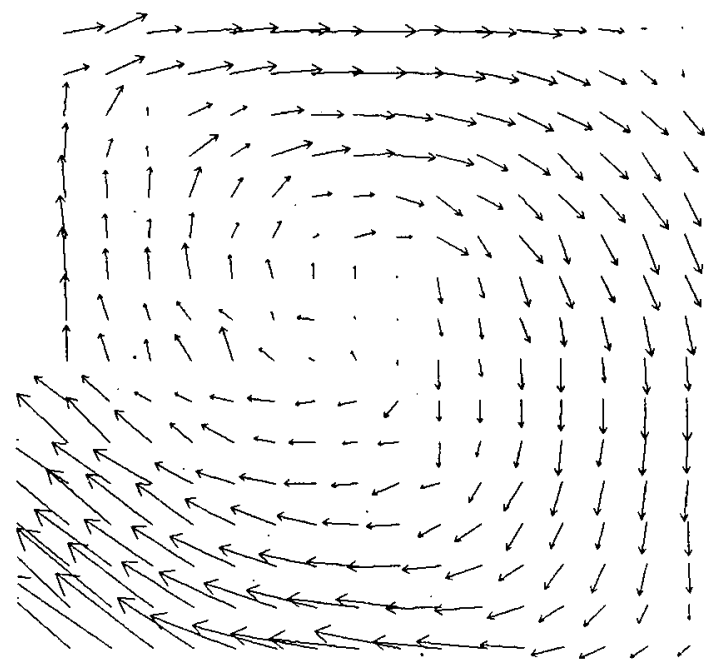

Fig.6 Measured velocity distribution using a modelbased technique.

このような流場モデルを用いた手法は、流れ場の物理 法則と計測の支配方程式を連立させて計測を行う場合が 多いが、時空間微分法は計測に用いる支配方程式が微分 方程式で記述されているため、運動方程式などの物理法 則との連立がとりやすく、このような手法に適しているも のと考えられる。

\section{7 ·結，言}

可視化画像の時空間微分を用いた流場の計測手法とそ の応用で、従来の計測手法の壁面摩摖応力計測一の応用や 統計的手法の適用、流場モデルを用いた新しい計測手法に ついて述べた。時空間微分法は、高い空間解像度を持ちな がらも、画像に対する制約やその特性があまり知られて いないため、必ずしも広く用いられていないのが現状で ある。本論文で示した新しい計測手法の可能性や応用が、 時空閣微分法の実用化に貢献できるものと期待する。

\section{参考文献}

[1] Horn, B.K.P. and Schunk, B.G., Determining Optical Flow, Artificial Intelligence, Vol.17, 1981, pp.185203.

[2] 安藤 繁, 画像の時空間微分算法を用いた速度ベクト ル分布計測システム, 計測自動制御学会論文集, Vol:22, No.12, 1986, pp.1330-1336.

[3] 古賀和利, 三池秀敏, 同画像の時空間相関に基づくオ プティカルフローの解析，電子情報通信学会論文集, J72-D 2, 1989, pp.507-516.

[4] 西尾 茂, 奥野武俊, 可視化画像の時空閒微分を利用 した流場の画像計測（第2 報） 一高次微分項を採用し た場合-, 関西造船拹会誌，第218号，1992，pp.41-45.

[5] 奥野武俊，中岡 淳，可視化画像の時空間微分を利用乙 た流場の画像計測，関西造船協会誌，第 215 号, 1991， pp.69-74.

[6] 奥野武俊，西尾 茂，堀内宏史，油膜を用いた限界流 線之壁面摩擦灾力の計測，日本造船学会論文集，第 176 号, 1994, pp.59-65.

[7] 西尾 茂, 奥野武俊, 平田奈美, 粒子の通過頻度を用い た流場の画像計測, 可視化情報学会誌, Vol.15, Suppl. No.2, 1995, pp.201-204

[8] 西尾 茂, 平田奈美, 奥野武俊, 粒子の通過頻度を 用いた流場の画像計測（第 2 報）- 2 次元速度場の計 測-，可視化情報学会誌，Vol.16, Suppl. No.1, 1996, pp.199-202.

[9] 杉井康彦，奥野武俊，西尾 茂，流場モデルを用いた 速度場の画像計测, 可視化情報学会誌, Vol.16. Suppl. No.1, 1996, 207-210. 